Quim. Nova, Vol. 36, No. 3, 484-488, 2013

\title{
QUÍMICA NOVA INTERATIVA - QNInt - O PORTAL DO CONHECIMENTO DA SBQ: CONECTANDO CIÊNCIA
}

\section{E EDUCAÇÃOO}

\author{
Guilherme Andrade Marson \\ Instituto de Química, Universidade de São Paulo, CP 26077, 05599-970 São Paulo - SP, Brasil \\ Eduardo Galembeck \\ Departamento de Bioquímica, Instituto de Biologia, Universidade Estadual de Campinas, Rua Monteiro Lobato, 255, 13083-862 \\ Campinas - SP, Brasil, \\ Jailson B. de Andrade* \\ Instituto de Química, Universidade Federal da Bahia, Campus Universitário de Ondina, 40170-290 Salvador - BA, Brasil
}

Recebido em 27/8/12; aceito em 13/9/12; publicado na web em 18/2/13

\begin{abstract}
QUÍMICA NOVA INTERATIVA - QNInt - THE KNOWLEDGE PORTAL OF THE BRAZILIAN CHEMICAL SOCIETY: CONNECTING SCIENCE TO EDUCATION. The Química Nova Interativa (QNInt) portal was launched in 2009 by the Brazilian Chemical Society (SBQ) to offer free quality content for broad audiences. QNInt provides peer-reviewed articles from SBQ journals on science \& society, chemical concepts, classroom activities and educational research. With 3,000,000 visits, QNInt also offers a unique library of interactive molecules. In the International Year of Chemistry QNInt served for distributing $\mathrm{pH}$ kits and registering data from IUPAC's Global Water Experiment, yielding Brazil the largest share of the global $\mathrm{pH}$ data set. The portal performance makes QNInt a valuable resource for connecting science to education.
\end{abstract}

Keywords: internet; diffusion of chemical knowledge; science popularization.

\section{INTRODUÇÃO}

Existem palavras que marcam estágios sociais, educacionais, científicos e/ou tecnológicos. Neste inicio do século XXI três palavras têm definido parte significativa da agenda: Sustentabilidade, Interdisciplinaridade e Inovação. Um dos fatos significativos no Brasil foi quando em 2001, o Ministério da Ciência e Tecnologia, MCT, incorporou uma nova letra I (de inovação) em suas atividades, elaborou o livro verde de C,T\&I e organizou uma Conferência Nacional em Ciência, Tecnologia e Inovação, cujo subtítulo era "Conhecimento e Inovação para o Futuro". ${ }^{1}$ Naquela época a Sociedade Brasileira de Química (SBQ) estava elaborando o documento Eixos Mobilizadores em Química ${ }^{1}$ e evidenciou que “...para o país dar um salto também em inovação é necessário um investimento significativo na formação de recursos humanos qualificados em profusão e em todos os níveis. Logo, o primeiro eixo mobilizador sugerido é: Formação de recursos humanos qualificados...". Dentre as ações associadas a este eixo, foi destacada a necessidade da SBQ incentivar programas de formação de docentes e o desenvolvimento de atividades com a participação de estudantes do nível médio. ${ }^{1}$

Várias ações ocorreram na primeira década do século XXI tendo como motivador a agenda da Sustentabilidade, Interdisciplinaridade e Inovação e, no caso específico da SBQ, "os Eixos Mobilizadores em Química”. Em 2009, a SBQ, entre outros, comemorou o sucesso de uma das linhas de ação, a editorial, definida desde a sua criação em 1977. O Journal of the Brazilian Chemical Society, JBCS, comemorava 20 anos de publicação ininterrupta. ${ }^{2,3}$ A Química Nova continuava inovando e atuando além dos limites de uma publicação cientifica de destaque. Auxiliava (e auxilia) a liderança da SBQ na formulação e divulgação de planos e políticas para a Química brasileira, ${ }^{4}$ e naquele ano estava sendo lançado um Número Especial voltado para o aproveitamento de recursos naturais e formação de recursos humanos para enfrentar os desafios do século XXI. ${ }^{4}$ Por outro lado, Química

*e-mail: jailsondeandrade@ufba.br
Nova na Escola continuava a publicar textos e a fomentar discussões profícuas visando à melhoria na educação brasileira.

Estava pronto o cenário para a SBQ ampliar, de forma inovadora, a sua linha editorial, com base nas propostas de uma Comissão criada pela Diretoria e Conselho em dezembro de 2008..$^{5}$ O lema que guiou a expansão editorial foi "Pensar como Cientista e Atuar como Professor!", ${ }^{3}$ reafirmando Ciência e Educação como os focos permanentes da atuação da SBQ. Com isto, Química Nova Interativa, QNInt, fora lançado para reforçar este lema e para servir de instrumento de conexão entre Ciência e Educação.

Com efeito, no Editorial que apresenta a QNInt está registrado o seguinte:

“...Estamos na era do conhecimento. A informação está disponivel amplamente, proveniente das mais variadas fontes $e$ de origem ora confiável ora enganosa. O maior desafio atual dos professores e estudantes não é obter a informação, mas sim separar a confiável, classificá-la e interpretá-la. Nesta nova era o manejo adequado da informação no processo educativo só será atingido através da integração da ciência, como forma de pensar, com o ensino. Esta conexão precisa ser feita em todos os níveis do processo, pois só assim será possível atingir uma nova era em que a intensificação da criatividade predomine. Neste jovem século, atingimos a convergência científica e tecnológica onde o foco é no tema e não na disciplina. ${ }^{6}$ Isto não significa o fim da disciplina, mas sim que as disciplinas precisam ser repensadas e reapresentadas com foco em temas atuais e amplos o suficiente para permitir conexões intra e interdisciplinares. Se nas décadas de 1980 e 1990 foi extremamente importante a criação (e inoculação nos currículos) das disciplinas Química Ambiental e Química Verde, hoje o desafio é inocular o Comportamento Verde, que deve ser muito mais amplo que uma disciplina, sendo transversal durante toda a formação do estudante, bem como na atuação profissional. 
A sustentabilidade deve representar a busca permanente pelo bem-estar humano, a satisfação das suas necessidades econômicas e sociais, sem o comprometimento do progresso, do ambiente e do sucesso das futuras gerações. Nesse novo cenário a segurança ambiental, segurança energética e segurança alimentar são temas atuais e amplos o suficiente para permitir a conexão entre ciência e educação, com abordagem intra, inter e multidisciplinares.

Os livros e grande parte do material bibliográfico disponível não suportam adequadamente a conexão e abordagem apresentadas neste texto. Nesse sentido, a SBQ, apresenta aos sócios e à sociedade em geral o seu novo projeto: Química Nova Interativa, QNInt. Uma flecha que mira o futuro. Uma concepção que pretende ser "uma metamorfose ambulante"! QNInt é o Portal do Conhecimento da $S B Q$, cujo objetivo é prover instrumentação para a formação em Química, acreditada, para utilização por estudantes e professores em todos os níveis de formação, primando pela iteratividade e a atualização das informações. Em resumo, a conexão entre Ciência e Educação já chegou à área de Química!"

Neste trabalho apresentamos o portal QNInt, partindo de sua implementação e descrição e discutindo seu papel como instrumento de divulgação da Química a partir da análise dos resultados com o portal para esta finalidade.

\section{ESTRUTURAÇÃO, IMPLEMENTAÇÃO E RESULTADOS GERAIS DE UTILIZAÇÃO DO PORTAL}

O QNInt foi estruturado a partir de uma plataforma já existente, desenvolvida para a Biblioteca Digital de Ciências (BDC). ${ }^{7}$ Foram feitos os devidos ajustes de implementação de novas funcionalidades para atender às demandas específicas sendo lançada, em junho de 2009, uma plataforma desenvolvida com as tecnologias computacionais PHP, Javascript e Ajax, e um banco de dados MySQL.

Nesses primeiros três anos de funcionamento, o primeiro fato que chama a atenção é o constante crescimento no número de visitas ao portal, superando a marca de 2 milhões de visitas, sendo que em julho de 2012 já ultrapassou a marca de 1 milhão de acessos. A Figura 1 mostra o número de visitas diárias ao portal, podendo ser facilmente verificado o crescimento no número de visitas.

Visitas diárias ao portal QNInt

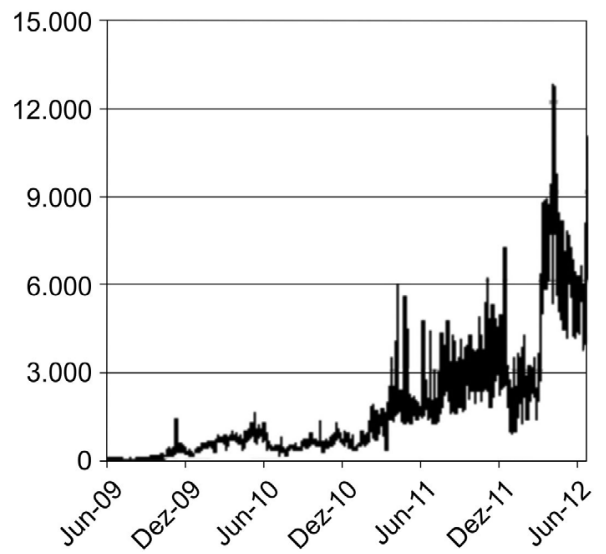

Figura 1. Visitas diárias ao portal QNInt no período compreendido entre $1 / 6 / 2009$ e 22/6/2012

O papel das novas tecnologias como instrumentos de ensino tem sido discutido já há algumas décadas e, inclusive, há um número razoável de propostas que levam em conta características próprias do conhecimento químico na concepção e utilização destes recursos para o ensino da Química. ${ }^{8,9}$

Alguns destes pressupostos foram levados em conta na forma como o QNInt organiza e articula as diferentes categorias de conteúdo disponíveis no portal, cujo conteúdo é, com exceção das categorias "moléculas interativas" e "sala de aula", proveniente exclusivamente das publicações da Sociedade Brasileira de Química (http:/www.sbq. org.br) - Química Nova na Escola (http://qnesc.sbq.org.br) e Química Nova (http://quimicanova.sbq.org.br). Na proposta do portal, isto é fundamental. Em primeiro lugar porque assegura a qualidade dos conteúdos e, em segundo lugar, porque faz do portal um produto da comunidade acadêmica química brasileira, já que se baseia fundamentalmente em trabalhos desta comunidade.

As categorias de conteúdo são sumarizadas a seguir:

a) conteúdos temáticos - buscam, em sua maioria, estabelecer correlações entre o contexto social, econômico e histórico e os conceitos químicos, atendendo, na medida do possível, preceitos do movimento Ciência Tecnologia e Sociedade;

b) conteúdos conceituais - buscam, em sua maioria, descrever e explicar um conceito químico em seus aspectos simbólicos, macroscópicos e submicroscópicos;

c) moléculas interativas - buscam fornecer um recurso para visualização de estrutura molecular, associando propriedades da substância a características moleculares, transitando assim nos eixos macroscópico e submicroscópico;

d) sala de aula - é uma categoria que traz coleções de artigos com sugestões metodológicas para tratar os conceitos químicos em sala de aula, incorporando conteúdos da Química Nova na Escola e também do portal Ponto Ciência (http://pontociencia.org.br);

e) pesquisa em ensino de química (PEQ) - é uma categoria que traz artigos versando sobre questões de ensino e aprendizagem e outros temas de interesse da pesquisa educacional, permitindo ao usuário do portal adentrar estas questões.

As diferentes categorias de conteúdo estão organizadas em seções distintas do portal relacionadas de forma hipertextual. Os temas podem ser considerados o eixo central desta organização, sendo o ponto de partida sugerido para articular e acessar outras categorias de conteúdos. Todavia, estas também podem ser acessadas direta e individualmente, permitindo diferentes percursos de exploração do portal. Na Tabela 1 são apresentados dados sobre o acesso a estas categorias de conteúdo do portal.

Tabela 1. Acessos às principais sessões do QNInt, em valores absolutos e proporcionais à quantidade de material em cada sessão. Dados coletados no período compreendido entre 1/6/2009 e 22/6/2012

\begin{tabular}{cccc}
\hline Sessão & Visitas & Conteúdos & Visitas/conteúdo \\
\hline Conceitos & 30257 & 43 & 703 \\
Molécula & 298818 & 353 & 864 \\
PEQ* & 10761 & 20 & 538 \\
Sala de Aula & 20304 & 34 & 597 \\
Tema & 538708 & 46 & 11711 \\
Materiais & 33882 & 18 & 1882 \\
\hline
\end{tabular}

*Pesquisa em Ensino de Química

A análise dos dados da Tabela 1 sugere que os usuários do QNInt interagem com o ambiente do portal a partir dos temas, os quais têm um número de acessos muito superior aos conteúdos pontuais.

O volume de conteúdo já disponível no QNInt evidencia a importância do mecanismo de busca do portal. O mecanismo de busca já 
foi utilizado mais de 500 mil vezes, sendo pesquisados mais de 3,3 mil termos diferentes, dentre os quais os de maior ocorrência estão listados na Tabela 2.

Tabela 2. Lista dos 15 termos mais procurados no mecanismo de busca do QNInt e quantidades de vezes que foram pesquisados. A grafia dos termos da tabela abaixo é a que foi digitada pelos usuários no mecanismo da busca. Dados coletados no período compreendido entre 1/6/2009 e 22/6/2012

\begin{tabular}{ccc}
\hline Posição & Termo pesquisado & Ocorrências \\
\hline 1 & termoquímica & 45 \\
2 & água & 41 \\
3 & tabela periódica & 41 \\
4 & calor & 28 \\
5 & química orgânica & 28 \\
6 & dissolução & 27 \\
7 & solubilidade & 26 \\
8 & Ph & 26 \\
9 & cromatografia & 24 \\
10 & pH do planeta & 24 \\
11 & ligações químicas & 22 \\
12 & equilíbrio químico & 20 \\
13 & Polímeros & 20 \\
14 & Colóides & 19 \\
15 & geometria molecular & 17 \\
\hline
\end{tabular}

Entre os termos mais pesquisados, destacam-se aqueles relacionados com o Experimento Global da Água ( "pH do Planeta" - discutido mais adiante), iniciativa cujo sucesso dependeu do uso do QNInt. A página do Experimento Global da Água foi concebida como uma seção do QNInt com acesso direto a partir da página principal do portal. Esta seção acumulou mais de 100 mil visitas e recebeu os resultados de cerca de 2,9 mil experimentos.

$\mathrm{O}$ acesso ao portal é livre e gratuito e poucas ações requerem o cadastro dos usuários. A compilação de informações fornecidas pelos mais de 3 mil usuários cadastrados revela que 39\% se identificam como estudante, $38 \%$ como professor e $9 \%$ como pesquisador. Os usuários cadastrados no QNInt são provenientes de todos os estados do Brasil, porém $50 \%$ dos usuários concentram-se na região sudeste (Tabela 3). Salienta-se a correlação direta com a distribuição da população brasileira nos estados.

\section{O PORTAL QUÍMICA NOVA INTERATIVA COMO INSTRUMENTO DE DIFUSÃO E PARTICIPAÇÃO}

É possível conceber três formas básicas de apropriação das tecnologias da informação e do conhecimento (TIC): informar, criar e comunicar. ${ }^{10}$ Em sua proposição original, o portal QNInt contempla essencialmente a função informativa, o que se observa essencialmente ao analisarmos os dados de acesso apresentados. Dado o fato da grande maioria dos conteúdos disponíveis ser originária de publicações da SBQ, à primeira vista, poderia transparecer que o portal teria apenas função replicadora de conteúdos já indexados em bases de dados e disponíveis diretamente em outros canais. Contudo, há de se considerar que a proposta de articulação destes conteúdos no portal altera significativamente a relação daqueles que o acessam com tais conteúdos, potencializando a sua difusão tanto no que se refere ao número de acessos quanto à abrangência do público-alvo.
Tabela 3. Distribuição dos usuários cadastrados na QNInt por estado. Dados coletados no período compreendido entre 1/6/2009 e 22/6/2012

\begin{tabular}{|c|c|c|}
\hline Estado & $\begin{array}{l}\text { Distribuição de usuários } \\
\text { cadastrados por estado, \% }\end{array}$ & $\begin{array}{l}\text { Distribuição da população } \\
\text { brasileira por estados, \% }\end{array}$ \\
\hline SP & 29,4 & 21,5 \\
\hline MG & 11,2 & 10,3 \\
\hline RJ & 10,2 & 8,2 \\
\hline BA & 7,6 & 7,3 \\
\hline PR & 4,4 & 5,5 \\
\hline RS & 4,2 & 5,7 \\
\hline $\mathrm{CE}$ & 4,1 & 4,4 \\
\hline $\mathrm{PE}$ & 3.3 & 4,6 \\
\hline GO & 2,9 & 3,1 \\
\hline $\mathrm{SC}$ & 2,7 & 3,3 \\
\hline MA & 2,2 & 3,5 \\
\hline $\mathrm{PA}$ & 2,0 & 4,0 \\
\hline RN & 1,8 & 1,7 \\
\hline $\mathrm{AL}$ & 1,7 & 1,7 \\
\hline DF & 1,6 & 1,3 \\
\hline ES & 1,5 & 1,8 \\
\hline SE & 1,4 & 1,1 \\
\hline $\mathrm{PB}$ & 1,2 & 2,0 \\
\hline MS & 1,2 & 1,3 \\
\hline $\mathrm{AM}$ & 1,2 & 1,8 \\
\hline MT & 1,1 & 1,6 \\
\hline PI & 1,0 & 1,7 \\
\hline TO & 0,4 & 0,7 \\
\hline $\mathrm{RR}$ & 0,4 & 0,2 \\
\hline $\mathrm{RO}$ & 0,3 & 0,8 \\
\hline $\mathrm{AP}$ & 0,3 & 0,3 \\
\hline $\mathrm{AC}$ & 0,2 & 0,4 \\
\hline
\end{tabular}

a dados referentes ao senso demográfico do IBGE de 2010, disponíveis em http://www.censo2010.ibge.gov.br/dados_divulgados/, acessada em Julho 2012

Um primeiro caso que ilustra a influência da publicação de conteúdos no portal sobre seu acesso é o caso do artigo "Ciclos Globais de Carbono, Nitrogênio e Enxofre: a Importância na Química da Atmosfera", ${ }^{11}$ publicado originalmente nos Cadernos Temáticos da Química Nova na Escola, em 2003. No QNInt, este conteúdo foi acessado mais de 158 mil vezes entre 2009 e 2012. Outro caso ilustrativo é o do artigo "Por que Todos os Nitratos são Solúveis?", ${ }^{12}$ publicado em Química Nova, em dezembro de 2004. No período de 2009 a 2012, este conteúdo recebeu 36 mil visitas no portal QNInt e 19 mil visitas no portal Scielo. Além do impacto da publicação no portal sobre o total de acessos, é relevante considerar também as diferenças entre os usuários do portal QNInt e da base Scielo. No QNInt, o artigo alcança público-alvo mais diverso, atingindo professores e alunos do ensino básico. Tal consideração sugere que o portal é um instrumento de difusão de conhecimento que possibilita a criação de novos canais de acesso do público geral às fontes primárias de conhecimento. Este atributo é particularmente importante na publicização de conhecimento científico, uma vez que as principais fontes de informação científicas de professores e alunos do sistema básico de ensino são, 
em sua maioria, fontes secundárias e terciárias de informação as quais, não raro, apresentam imprecisões advindas dos processos de generalização e simplificação dos conteúdos originais. No QNInt, portanto, no tocante ao objetivo da difusão de conhecimento científico, a função informativa das TIC é contemplada de forma distinta, tanto quantitativa quanto qualitativamente.

A função informativa do QNInt é de grande valia para o propósito de difusão de informação científica. Contudo, há de se considerar que a consecução de objetivos mais persistentes de enculturação científica requer ações participativas articuladas ao sistema básico de ensino, que extrapolam o âmbito da difusão de informações. Coloca-se, portanto, para o QNInt, a necessidade de servir também como instrumento para ações desta natureza. A prova de conceito da utilização do QNInt para tais iniciativas foi seu uso como instrumento de articulação do Experimento Global da Água no Brasil durante o Ano Internacional da Química (AIQ) em 2011, que foi a principal iniciativa da IUPAC no AIQ. Consistiu em envolver as comunidades escolares na determinação experimental de parâmetros relacionados à potabilidade da água, dentre os quais, a determinação do $\mathrm{pH}$ por comparação de cores valendo-se de uma escala de calibração e de soluções dos indicadores púrpura de metacresol e azul de bromotimol.

No Brasil, o experimento global foi lançado como " $\mathrm{pH}$ do Planeta" e incluiu a distribuição de um kit simples com os indicadores e a escala de cores. O QNInt centralizou o cadastro de professores, a solicitação de kits de medida de $\mathrm{pH}$ e o registro dos resultados obtidos por comunidades em todo o Brasil. A Figura 2 sumariza os resultados da iniciativa, indicando que os objetivos da iniciativa foram satisfatoriamente contemplados.

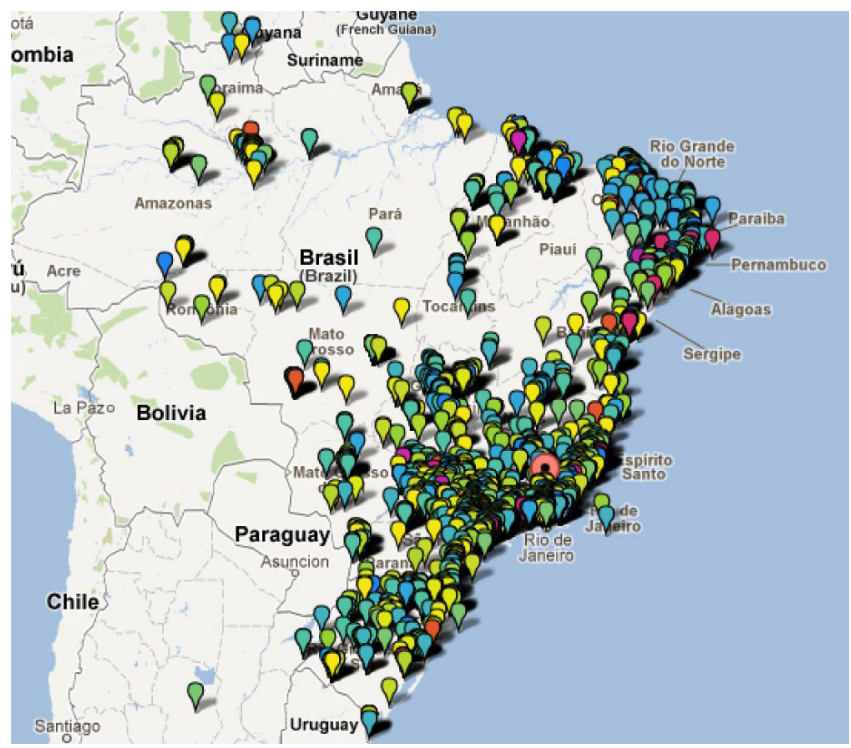

Figura 2. Mapa indicando a distribuição dos 2904 resultados enviados pelos participantes do experimento em 644 municípios brasileiros. Os pontos são coloridos segundo valores da escala adotada no experimento (http://QNInt. sbq.org.br/agua/mapa.php)

Os dados apresentados no mapa reúnem resultados obtidos no curto espaço de tempo entre o lançamento da iniciativa em abril de 2011 e março de 2012. Dados disponíveis no web site do Experimento Global da Água indicam a participação de 75 países, resultando em 2654 experimentos envolvendo 64959 estudantes. Tais resultados estão sumarizados na Tabela 4.

O cenário apresentado na Tabela 4 indica que a participação do Brasil, nas medidas de $\mathrm{pH}$ do Experimento Global, foi numericamente a mais significativa no corpo de resultados de experimentos
Tabela 4. Dados referentes à medida de $\mathrm{pH}$ para o Experimento Global da Água em diversos países

\begin{tabular}{lccc}
\hline \multirow{2}{*}{ País } & \multicolumn{2}{c}{ Contribuição de cada país } & Estudantes por \\
\cline { 2 - 3 } & $\begin{array}{c}\text { \% experimentos } \\
n=2654\end{array}$ & $\begin{array}{c}\% \text { estudantes } \\
n=64959\end{array}$ & experimento \\
\hline Brasil & 28 & 29 & 25 \\
Reino Unido & 7 & 12 & 41 \\
EUA & 11 & 10 & 21 \\
Espanha & 5 & 9 & 41 \\
Croácia & 5 & 5 & 24 \\
Filipinas & 1 & 3 & 61 \\
Porto Rico & 2 & 3 & 33 \\
Outros ${ }^{a}$ & 41 & 29 & - \\
\hline & Súmula dos resultados ${ }^{\mathrm{b}}$ & \\
\hline Média & 1 & 1 & 20 \\
Mínimo & 0,04 & 0,002 & 0,5 \\
Máximo & 28 & 29 & 61 \\
Moda & 0,04 & 0,02 & 10 \\
\hline
\end{tabular}

Fonte: web site do Experimento Global da Água (http://water.chemistry2011. org/web/iyc/visualisation, acessada em Julho2012). ${ }^{\text {a } O ~ g r u p o ~ " o u t r o s " ~ r e u ́ n e ~}$ dados de países com menos de $3 \%$ do total mundial de estudantes participantes.

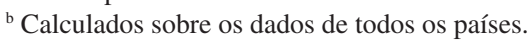

computados pela IUPAC e no número de estudantes participantes. É particularmente notável que países com sistemas educacionais mais bem estruturados e que ocupam posições de liderança científica, como os EUA e o Reino Unido, aparentemente não obtiveram o mesmo êxito. Isto é especialmente interessante na comparação entre os resultados do Brasil e dos EUA, países continentais populosos bastante distintos quanto ao produto interno bruto, ao investimento em ciência e tecnologia e ao investimento per capita em educação básica. Embora os motivos destes resultados careçam de investigação apropriada para serem elucidados, é plausível supor que a contribuição de instrumentos como o QNInt aliados à intensa articulação que se deu na comunidade brasileira tenham sido fatores decisivos.

Assim, pode-se considerar com boa margem que estes resultados indicam que o QNInt serviu como instrumento eficaz para a articulação da iniciativa, a qual explorou em boa medida o potencial do portal como ferramenta de comunicação. Associado à proposta do Experimento Global, o QNInt possibilitou que as comunidades escolares brasileiras participassem de um experimento real e que os resultados obtidos tivessem uma dimensão pública instantânea. Adicionalmente, a plataforma de submissão dos resultados permitiu a inserção de dados sobre o experimento e até a fotografia dos alunos participantes. Portanto, é razoável admitir que, em seu todo, o conjunto dos resultados do Experimento Global no QNInt constitui um panorama do movimento de difusão científica e participação efetiva de comunidades escolares em nível nacional. Demonstra, portanto, que a articulação de iniciativas como o Experimento Global a ferramentas consolidadas de difusão científica pode ser um valioso instrumento de enculturação científica. $O$ fato deste instrumento ter sua gênese e gestão no seio de uma sociedade científica agrega ainda mais valor à iniciativa, pelas seguintes razões: em primeiro lugar, possibilita que ações de longo prazo sejam planejadas em circunstâncias menos susceptíveis às flutuações das políticas de estado; em segundo, favorece o estabelecimento de canais diretos de comunicação entre cientistas e a sociedade; em terceiro, proporciona resultados capazes de sensibilizar a comunidade científica para valorizar este tipo de 
ação, de modo que possa atender à demanda crescente da sociedade por esclarecimentos sobre o papel da ciência e sobre a função social dos centros públicos de pesquisa e ensino das ciências.

\section{COMENTÁRIOS FINAIS}

Os resultados apresentados são indicativos de que o portal QNInt é um recurso estabelecido e bem sucedido de divulgação do conhecimento químico. Objetivos de difusão de conhecimento tornam-se, por meio do portal QNInt, realidade, evidenciando que uma das metas da SBQ, registrada nos "Eixos Mobilizadores em Química", ${ }^{1}$ foi atingida. Contudo, o estado ainda incipiente de conscientização científica da população constitui desafio à altura dos esforços da Sociedade Brasileira de Química e dos meios de que dispõem para superá-los. Com vistas ao futuro, novas empreitadas estão em andamento, como os "Desafios QNInt" (http://qnint.sbq. org.br/desafios/) e outras emergirão como respostas aos desafios que estão por vir. Assim, a Sociedade Brasileira de Química continua caminhando, em passos largos, rumo ao futuro.

\section{AGRADECIMENTOS}

Ao inestimável apoio da Diretoria e Conselho da SBQ e do trabalho dedicado e competente de A. C. Pinto (UFRJ), A. Moura (UFSCar), C. Zucco (UFSC), L. A. Silva (UFBA), P. C. Vieira (UFSCar), P. Tiedemann (USP), R. Epifânio (UFF), S. I. Córdoba de Torresi (USP), V. Bolzani (UNESP) e V. L. Pardini (USP).

\section{REFERÊNCIAS}

1. de Andrade, J. B.; Cadore, S.; Vieira, P. C.; Zucco, C.; Pinto, A. C.; Quim. Nova 2003, 26, 445.

2. de Andrade, J. B.; J. Braz. Chem. Soc. 2009, 20(1), iii.

3. de Andrade, J. B.; J. Braz. Chem. Soc. 2009, 20(4), iv.

4. Galembeck, F.; Pardini, V. L.; Quim. Nova 2009, 32, 565.

5. A Comissão foi inicialmente composta por Jailson B. de Andrade, Coordenador (UFBA), Angelo C. Pinto (UFRJ), Cesar Zucco (UFSC), Paulo C. Vieira (UFSCar), Susana I. Córdoba de Torresi (USP) e Vera L. Pardini (USP). Foi ampliada com o andamento dos trabalhos, contando com a inestimável colaboração de Vanderlan Bolzani (UNESP), Eduardo Galembeck (UNICAMP), Guilherme Marson (USP), Luciana A. Silva (UFBA), Peter Tiedemann (USP), Rosangela Epifânio (UFF) e André Moura (UFSCar)

6. Pinto, A. C.; Zucco, C.; de Andrade, J. B.; Vieira, P. C.; Quim. Nova 2009, 32, 567.

7. http://www.bdc.ib.unicamp.br, acessada em Julho 2012.

8. Marson, G., A.; Torres, B. B.; J. Chem. Educ. 2011, 88, 1616.

9. Costa, M. J. ; Galembeck, E.; Marson, G. A. ; Torres, B. B.; Lewitter, F.; PLoS Comput. Biol. 2008, 4, e1000035.

10. Giordan, M.; Educ. Pesqui. 2005, 31, 57.

11. Martins, C. R.; Pereira, P. A. de P.; Lopes, W. A.; de Andrade, J. B.; QNESC 2003, Caderno Temático 5, 28.

12. Silva, L. A.; Martins, C. R.; de Andrade, J. B.; Quim. Nova 2004, 27, 1016. 